УДК $316.4 ; 316.334: 61$

ЕВСЕЕВА Я.В.* ЭВТАНАЗИЯ: ИСТОРИЯ И СОВРЕМЕННЫЕ ДЕБАТЫ. (Обзор). DOI: 10.31249/rsoc/2021.03.02

Аннотация. В данном обзоре прослеживается история идеи эвтаназии, а также рассматриваются некоторые аспекты современных практик содействия добровольному уходу из жизни, а именно: определение и содержательное наполнение понятия «эвтаназия»; дебаты сторонников эвтаназии и паллиативного ухода; кросскультурные различия в отношении к эвтаназии; развитие практики эвтаназии на примере Нидерландов; эвтаназия пациентов, страдающих психиатрическими заболеваниями.

Ключевые слова: смерть; эвтаназия; ассистированный суицид; паллиативный уход; законодательство об эвтаназии; автономия; психиатрия; Нидерланды.

EVSEEVA Ya.V. Euthanasia: history and modern debates. (Literature review).

Abstract. The present review traces the history of the idea of euthanasia as well as considers some aspects of its contemporary practice, namely: definition and semantics of the notion "euthanasia»; debates of advocates of euthanasia and palliative care, respectively; cross-cultural differences in attitudes toward euthanasia; developments in euthanasia practice (using the example of the Netherlands); euthanasia for psychiatric patients.

Keywords: death; euthanasia; assisted suicide; palliative care; euthanasia legislation; autonomy; psychiatry; the Netherlands.

* Евсеева Ярослава Вячеславовна - старший научный сотрудник отдела социологии и социальной психологии Института научной информации по общественным наукам PAH. E-mail: yar_evseeva@mail.ru 
Для цитирования: Евсеева Я.В. Эвтаназия: история и современные дебаты. (Обзор) // Социальные и гуманитарные науки. Отечественная и зарубежная литература. Сер. 11: Социология. - 2021. - № 3. - С. 12-25. DOI: $10.31249 / \mathrm{rsoc} / 2021.03 .02$

Под эвтаназией (от греч. «хорошая смерть») обычно понимается прекращение жизни человека (данный термин может использоваться также в отношении домашних животных, однако в настоящем обзоре речь пойдет о людях), страдающего неизлечимым заболеванием (что лишает лечение смысла) и в большинстве случаев испытывающего нестерпимые физические и моральные мучения ${ }^{1}$. Помимо «эвтаназии» используется также такой термин, как «ассистированный суицид» (assisted suicide), под чем понимается практика, при которой не врач, а сам пациент прекращает свою жизнь с помощью врача, назначающего либо предоставляющего необходимый препарат, или, иначе, «смерть с врачебной помощью» (assisted dying) (по мнению сторонников употребления этого термина, он не несет в себе негативных коннотаций, заключенных в слове «самоубийство»; кроме того, самоубийство - это то, что врачи и психологи должны предотвращать, в отличие от эвтаназии [Inbadas, Carrasco, Clark, 2020]). В разных странах распространены разные наименования. Так, в США принято обозначение «ассистированный суицид», поскольку в нескольких штатах законодательно разрешена именно эта практика [Attitudes toward euthanasia, 2021].

Эвтаназия известна с древности (подробнее об истории данного феномена с древних времен до наших дней см., например: [Biotti-Mache, 2016]), что отражено в многочисленных свидетельствах древнегреческих и древнеримских авторов и на что, в частности, указывает фраза из клятвы Гиппократа: «Я не дам никому просимого у меня смертельного средства и не покажу пути для подобного замысла». В современном понимании слово «эвтаназия» в своем труде 1605 г. «The advancement of learning» («О достоинстве и приумножении наук») впервые употребил Фрэнсис Бэкон, описавший ее как прекрасную (справедливую) и легкую смерть («a fair and easy passage» [цит. по: ibid., p. VI]). При этом с

${ }^{1}$ Cм., напр.: Euthanasia. - URL: https://en.wikipedia.org/wiki/Euthanasia (accessed: 12.06 .2021$)$. 


\section{Евсеева Я.В.}

юридической точки зрения эвтаназия неизменно отождествлялась с убийством / самоубийством. В начале XX в., в частности в США, затем в Советской России, были предприняты попытки декриминализировать эвтаназию, однако они не увенчались успехом. Нацистские опыты на людях дискредитировали подобные медицинские практики и на некоторое время остановили обсуждение этого вопроса. Однако в 1960-1970-е годы, с активизацией борьбы за права человека, ростом ценности частной жизни и свободы выбора, на фоне все большей секуляризации общества, вновь зазвучали призывы позволить прекращать жизнь в случае невозможности излечения и невыносимости страданий [Developments in euthanasia practice ..., 2019]. Впервые эвтаназия в форме ассистированного суицида (врач имеет право выписать смертельное средство по просьбе пациента) была легализована в США, в штате Орегон, в 1994 г. (практика начала осуществляться в 1997 г.); позже аналогичное законодательство вступило в силу в штатах Вашингтон, Монтана, Вермонт, Калифорния, Колорадо, Мэн, НьюДжерси, Гавайи и Нью-Мексико и в округе Колумбия. К настоящему времени ассистированный суицид легализован также в Швейцарии, Канаде, Испании, в нескольких штатах Австралии и будет легализован в ближайшее время в еще ряде стран. В полной мере (врач сам имеет право ввести соответствующий препарат) эвтаназия была впервые разрешена в 2001 г. в Нидерландах (притом что декриминализирована эта практика здесь была еще в 1984 г.), затем в Бельгии (2002) и в Люксембурге (2008). В представлении многих именно Нидерланды ассоциируются с легализацией эвтаназии, и практике эвтаназии в этой стране посвящено наибольшее количество научных и публицистических материалов.

Также говорят о добровольной и недобровольной эвтаназии. В первом случае пациент отчетливо высказывает желание, чтобы его жизнь была прекращена до того, как это произойдет естественным образом. Во втором случае он находится в бессознательном состоянии. Тогда решение о завершении жизни принимается родственниками и / или медицинской бригадой [см.: Koksvik, 2020]. Здесь речь чаще всего идет о так называемой пассивной эвтаназии. При активной эвтаназии врач (либо сам пациент при ассистированном суициде) своими действиями непосредственно прекращает жизнь (в частности, вводит смертельную дозу того или иного ве- 
щества), тогда как при пассивной эвтаназии он лишь не прибегает к действиям, способствующим поддержанию жизни (не назначает или прерывает лечение, не проводит операцию, новый курс химиотерапии, реанимацию и пр.). В странах, в которых эвтаназия запрещена законодательно (к каковым относится и Российская Федерация), под эвтаназией понимают, прежде всего, именно активную эвтаназию, поскольку исключительно воздержание от лечения неизлечимо больного человека значительно сложнее проконтролировать и тем более квалифицировать как умышленное убийство. Тем не менее ряд стран (например, скандинавские страны) в настоящее время не оставляют пробела в законодательстве, запрещая активную, но разрешая пассивную эвтаназию [см., например: Biotti-Mache, 2016].

Исследователи из Университета Глазго (Великобритания) Гамильтон Инбадас, Хосе Мигель Карраско и Дэвид Кларк изучают нюансы понимания эвтаназии и самоубийства / смерти с врачебной помощью, с одной стороны, и, с другой стороны, паллиативного ухода (который представляет собой помощь неизлечимо больному пациенту, направленную на купирование симптомов и облегчение физических и моральных страданий вплоть до естественного конца жизни) [Inbadas, Carrasco, Clark, 2020]. Они изучили 104 документа (декларации, хартии, манифесты, резолюции) от 1974-2017 гг., подготовленные сторонниками того или иного способа обращения со страждущими умирающими, выделив три направления интерпретации рассматриваемых феноменов: 1) концептуализация; 2) индивидуальная и социальная значимость; 3) стратегии будущего развития.

Как отмечают Инбадас и его коллеги, противостояние сторонников эвтаназии и паллиативного ухода насчитывает не одно десятилетие. Практически все основатели хосписного движения и паллиативной медицинской помощи, чья система сложилась в середине XX в., были убежденными противниками прерывания жизни «по запросу» как по моральным, так и по профессиональным причинам (совершенствование паллиативного ухода способствует развитию медицины, в отличие от эвтаназии), и подобное отношение во многом сохранилось и впоследствии. Со своей стороны, сторонники эвтаназии / ассистированного суицида делали акцент на правах человека (а именно праве распоряжаться своей жизнью, 


\section{Евсеева Я.В.}

а значит, и смертью). Авторы статьи обнаружили, что из отобранных ими документов в 81 (78\%) поддерживалась паллиативная помощь и / или критиковалась эвтаназия, в 14 (13\%) содержалась нейтральная позиция, и в 9 (9\%) отстаивалось право на эвтаназию в той или иной форме.

Паллиативную помощь ее сторонники определяли как «подход, который повышает качество жизни пациентов и их семей, предотвращая и облегчая страдания благодаря ранней диагностике и терапии болевых ощущений, а также решению различных физических, психосоциальных и духовных проблем» [Inbadas, Carrasco, Clark, 2020, p. 141]. Они видели в ней неотъемлемое право, в то время как нарушением прав является, с их точки зрения, как раз неоказание адекватной паллиативной помощи, что может подтолкнуть человека к эвтаназии. Со своей стороны, их оппоненты полагали, что у человека есть право на отказ от продления страданий в рамках паллиативного ухода и на радикальное разрешение данной жизненной ситуации. Нейтральные определения эвтаназии связаны с прекращением жизни врачом (с врачебной помощью) / умерщвлением пациента по его просьбе. Ее противники определяли ее как убийство пациента, а сторонники - как введение смертельного средства с целью прекращения невыносимых страданий неизлечимо больного человека, благодаря чему, по их мнению, реализуется фундаментальное человеческое право. Некоторые сторонники эвтаназии демонстрировали достаточно узкое понимание данного феномена, во многом исключая пассивную эвтаназию из спектра ее проявлений и утверждая, что к эвтаназии не относятся не только повлекшие смерть пациента врачебные ошибки, но и прекращение лечения по просьбе пациента, а также собственное решение врача о воздержании от медицинской помощи.

Следующий аспект касался значения рассматриваемых феноменов для индивидуального жизненного опыта, медицинской практики и обществ в целом. Положительное значение паллиативного ухода виделось в том, что он облегчает страдания, повышает качество жизни умирающих пациентов, способствует повышению профессиональной подготовки врачей различных специальностей. Отрицательную роль / отсутствие положительной роли данной практики усматривали в том, что на деле облегчение страданий подчас носит лишь частичный характер, а все более глубокая се- 
дация и постоянное повышение доз морфина по сути мало отличаются от эвтаназии - они просто отнимают несколько больше времени. Индивидуальная и социальная значимость эвтаназии, по мнению ее сторонников, состоит в том, что она обеспечивает спокойный и достойный уход. Ее противники же выдвигали следующие контраргументы: эвтаназия может быть использована в преступных целях; человек может ощущать давление семьи и общества и, не желая быть обузой, может решиться на эвтаназию, раз уж она доступна; эвтаназия может стать негативным прецедентом: если умерщвление человека будет использоваться в качестве решения одной проблемы, могут найтись и другие проблемы, для которых оно также послужит решением.

Наконец, сторонники обеих практик описывали желательные сценарии их будущего развития и меры, которые необходимо для этого предпринять. Сторонники паллиативного ухода выступали за: повышение качества специального обучения медицинских работников; развитие сферы соответствующих услуг (для чего нужно повышать осведомленность общественности о данной сфере, повышать ее статус среди медицинских специализаций, расширять сеть учреждений, оказывающих данные услуги), изменение политики в этой области (развитие посвященного ей законодательства, включая облегчение доступа к сильнодействующим седативным и обезболивающим средствам) и привлечение необходимых ресурсов (в частности, расширение финансирования исследований и практики в данной области). Аналогичные требования выдвигали и сторонники эвтаназии, а именно: соответствующее обучение медицинских работников; широкие общественные дискуссии по поводу этой практики (и материальное обеспечение таких дискуссий); разработка законодательства, обеспечивающего свободный выбор врачей и пациентов и в то же время препятствующего использованию эвтаназии в каких-либо целях, кроме прекращения страданий в конце жизни.

Проведенное исследование, указывают Г. Инбадас и его коллеги, продемонстрировало отсутствие как единого определения эвтаназии, так и консенсуса по поводу содержательного наполнения данного понятия, в частности относится ли к эвтаназии воздержание от лечения или, скажем, насколько глубокой должна быть седация (насколько высокими должны быть дозы обезболи- 


\section{Евсеева Я.В.}

вающих препаратов), чтобы считаться уже скорее медленной эвтаназией, нежели паллиативным уходом. К ограничениям исследования, по словам авторов, можно отнести то, что они не рассматривали позицию семьи пациента, а также то, что все проанализированные документы имеют дело с западными практиками, а они отличаются от тех, что характерны для Глобального Юга.

Одно из крупнейших международных лонгитюдных исследований отношения к эвтаназии было проведено в рамках Всемирного обзора ценностей (World values survey) между 1981 и 2018 г. Освещая его результаты, Рональд Чарльз Инглхарт и его коллеги из Университета штата Огайо (г. Колумбус, США) Райан Нэш, Кияс Хасан и Джудит Шварцбаум связывают различия в отношении к эвтаназии с действием трех типов факторов - экономических, культурных и медицинских [Attitudes toward euthanasia, 2021].

В 2018 г. завершилась седьмая волна Всемирного обзора ценностей (всего было опрошено 389243 респондента из 109 стран). В настоящее исследование были включены данные из 62 стран, жители которых приняли участие в не менее чем трех волнах опросов. Среди задававшихся вопросов был и вопрос об эвтаназии, который звучал следующим образом: «Эвтаназию можно оправдать, нельзя оправдать, либо можно оправдать в одних случаях, а в других нельзя?» Ответы располагались на шкале от 1 («нельзя оправдать никогда») до 10 («можно оправдать всегда»).

В рамках седьмой волны опросов наиболее позитивное отношение продемонстрировали жители Нидерландов (средний балл 7,5), наиболее негативное - респонденты из Иордании (средний балл $-1,5)$. В 10 из 24 стран с высоким уровнем доходов (в соответствии с классификацией Всемирного банка) средний балл составлял выше шести (еще в восьми - выше пяти), а в 36 из 38 стран со средним и низким уровнем доходов - ниже пяти (здесь средний балл выше шести был характерен только для Чехии). Все страны с высоким уровнем доходов, за исключением Греции, продемонстрировали улучшение отношения к эвтаназии на протяжении времени (от первой волны, в которой принимали участие жители этой страны, до последней на данный момент); вместе с тем в ряде стран с низким уровнем доходов отношение ухудшилось (так, в Армении средний балл снизился с 4,24 до 2,78, в Азербайджане - с 
3,43 до 2,32). Среди культурных факторов наибольшее значение имел фактор религиозности: чем чаще респондент посещал религиозные службы, тем менее оправданной ему представлялась эвтаназия. Медицинские факторы включали в себя показатели детской смертности, ожидаемую продолжительность жизни в 1970 г. и историю паразитарных заболеваний в стране: чем выше были первые и ниже вторые показатели и чем более тяжелой была эта история, тем негативнее было отношение к эвтаназии.

Ухудшение отношения к эвтаназии авторы связывают с ухудшением экономической ситуации в стране и, соответственно, снижением качества медицинских услуг (постсоциалистические государства после падения коммунистических режимов, Греция во время экономического кризиса), а также повышением религиозности, в частности религиозным возрождением в ряде постсоциалистических стран. Для стран с высоким уровнем доходов типичны развитые, стабильные системы здравоохранения, в которых есть место разным формам окончания жизни; кроме того, во многих из этих стран в последние годы наблюдается либерализация законодательства, посвященного эвтаназии, и их население воспринимает ее как все более обычное явление. Однако, отмечают авторы, нельзя забывать, в скольких странах эвтаназия вызывает, в том числе все большее, неприятие. Помимо этого, внутри одной страны (как, например, в США) могут прослеживаться значительные различия экономического, культурного и медицинского характера, что также обусловливает разное отношение к эвтаназии, и это должны учитывать медицинские работники, занимающиеся данной практикой (не говоря уже о том, что и в страны с высоким уровнем доходов прибывает все больше медицинских работников из стран с негативным отношением к эвтаназии). Наконец, Р.Ч. Инглхарт и его коллеги полагают, что пандемия COVID-19 также может оказать влияние на практику эвтаназии в будущем, как и на отношение к ней.

Особый интерес у общественности и ученых вызывает практика применения эвтаназии в Нидерландах, как стране, находящейся в авангарде тенденций, связанных с легализацией содействия добровольному уходу из жизни. Развитие данной практики в этой стране прослеживают исследователи из Утрехтского университета (Нидерланды) Паулина Каувенховен, Гислен ван Тиль и 


\section{Евсеева Я.В.}

Йоханнес ван Дельден и их коллеги из Университета им. Эразма Роттердамского (г. Роттердам, Нидерланды) Агнес ван дер Хейде и Юдит Ритьенс [Developments in euthanasia practice ..., 2019]. Как сообщают авторы, в 2015 г. 4,5\% смертей в Нидерландах произошли в результате эвтаназии (для сравнения: в 2005 г. - 1,7\%) и $93 \%$ данных процедур были осуществлены терапевтом. В $80 \%$ решение об эвтаназии было принято исходя из выраженного желания пациентов, причем среди причин, выдвигаемых последними, неизлечимость болезни опережала невыносимость боли. Этот факт, по мнению авторов, свидетельствует о том, что люди все больше стремятся контролировать собственную жизнь, в том числе и ее конец.

В 2002 г. вступил в силу законодательный акт, регулирующий осуществление практики эвтаназии. Согласно этому акту, врач, проводящий эвтаназию, обязан удостовериться, что соблюдаются следующие требования: желание пациента является добровольным и обдуманным; страдания пациента невыносимы, а лечение бесперспективно; пациент полностью проинформирован о своем состоянии и шансах на излечение; врач и пациент вместе пришли к заключению, что иного способа облегчить страдания последнего не существует; пациента проконсультировал, по крайней мере, еще один врач, составивший письменное заключение о качестве проводимого лечения; эвтаназия (либо ассистированный суицид) проводится на самом высоком профессиональном уровне.

Однако многие врачи были настроены против эвтаназии, и не все пациенты получали согласие на свою просьбу о прекращении жизни. Как ответ на общественный запрос, в 2012 г. Nederlandse Vereniging voor een Vrijwillig Levenseinde (NVVE, Нидерландское общество права на смерть) открыло в Гааге Levenseindekliniek (клинику конца жизни), чей персонал обязан выносить свое решение исключительно на основе объективных критериев (неизлечимость болезни и невыносимость страданий), без учета собственных соображений морального или какого-либо иного свойства; в результате, здесь осуществляется больше процедур эвтаназии и ассистированного суицида, чем в других клиниках страны.

Тем не менее практика эвтаназии получила в Нидерландах дальнейшее развитие. К началу 1990-х годов относятся первые 
инициативы по еще большей либерализации эвтаназии. Так, в 1991 г. бывший профессор гражданского права и член Верховного суда Нидерландов Хюйб Дрион предложил позволить, без дознаний и разбирательств, умирать всем больным людям старше 75 лет, которые устали от жизни и не видят смысла в ее продолжении (для этого он придумал специальный двухкомпонентный препарат, лишь второй, принимаемый через несколько дней после первого компонент которого будет смертелен, на случай недостаточно обдуманного решения). Проект не был реализован, но положил начало дискуссиям о том, не является ли пожилой возраст сам по себе достаточным основанием для желания умереть, если человек устал от жизни и не желает ее продолжения. В 2010 г. более 100 тысяч человек подписали петицию, призывавшую власти страны распространить законодательство об эвтаназии на людей, считающих свою жизнь завершенной [подробнее см.: van der Geest, Satalkar, 2019]. В 2016 г. специальная правительственная комиссия постановила, что существующее законодательство отвечает интересам большинства людей, обращающихся с просьбой об эвтаназии, поэтому на данный момент не нуждается в пересмотре. Однако Каувенховен и ее коллеги полагают, что данный процесс отнюдь не завершен, и тренд на все большую автономию, в частности в вопросе окончания жизни, будет лишь усиливаться.

Начиная с 1960-х годов, отмечают авторы статьи, понятие автономии приобретает все большую важность в медицинском праве. При этом автономию часто подразделяют на негативную и позитивную. В первом случае речь идет о свободе от воздействия внешних факторов. Желание индивида самому контролировать все аспекты своей жизни вплоть до смерти становится основополагающим; в результате роль врача начинает носить скорее инструментальный характер, ведь он фактически обязан предоставить эвтаназию во всех ситуациях, когда ее применение не противоречит действующему законодательству. Во втором случае автономия рассматривается как своего рода человеческий идеал, как способность проявлять гибкость, адаптироваться и развиваться. В соответствии с данным представлением об автономии, индивид принимает то, что посылает ему жизнь и готов справляться с жизненными трудностями и вызовами. Решения, в том числе жизненно важные, он принимает, ориентируясь не только на соб- 


\section{Евсеева Я.В.}

ственное желание ни от кого не зависеть и все контролировать, но и на советы родственников и заключение врача, который, возможно, предпочел бы продолжить лечение или прибегнуть к паллиативной помощи. Каувенховен и ее коллеги считают, что если мнение врача ценится, он имеет возможность найти оптимальный баланс между уважением автономии пациента и соблюдением собственных профессиональных обязанностей.

Отдельным вопросом идеи и практики эвтаназии является прекращение жизни психиатрических пациентов, когда психиатрические проблемы являются основной либо единственной причиной запроса об эвтаназии. Невыносимость физических страданий общепризнанное основание для эвтаназии, независимо от ее принятия или непринятия, а как насчет людей, годами либо десятилетиями страдающих от депрессии или биполярного расстройства и воспринимающих свое состояние как не менее тяжелое? Консультация психиатра показана при рассмотрении каждого случая, но здесь она имеет первостепенное значение. С какими проблемами в таких случаях сталкиваются психиатры и терапевты и как они принимают решение об эвтаназии, анализируют нидерландские исследователи из Амстердамского университета Розали Пронк, Дик Виллемс и Сюзан ван де Ватхорст [Pronk, Willems, van de Vathorst, 2021].

Как отмечают авторы, в Нидерландах психиатрические пациенты включены в практику эвтаназии и ассистированного суицида, поскольку решающее значение имеет непереносимость страданий, а не их источник. Тем не менее широкая общественность значительно настороженнее относится к прерыванию жизни «по запросу» для этих больных: если эвтаназию в целом, согласно опросам, поддерживают порядка 88\% населения, то эвтаназию для пациентов, страдающих психиатрическими заболеваниями, - только 53\% [Pronk, Willems, van de Vathorst, 2021, p. 269]. Такое же отношение характерно и для самих психиатров, основной причиной чего является сложность различения потребности в эвтаназии, с одной стороны, и суицидальных тенденций - с другой. А попытки суицида врачи, в соответствии с принятой врачебной этикой, должны предотвращать. Таким образом, терапевты и психиатры должны быть уверены, что пациент, имеющий психиатрическое заболевание (или несколько таковых), испытывает невыносимые 
страдания, что лечение его бесперспективно и что его просьба об эвтаназии в полной мере осознана. В рамках данного исследования Пронк и ее коллеги рассматривали только те случаи, когда душевная болезнь не сопровождалась какими-либо соматическими отклонениями.

В январе - июне 2016 г. были проведены интервью с психиатрами, а сентябре 2018 - феврале 2019 г. - с терапевтами. В окончательную выборку, репрезентативную по полу, специализации, опыту проведения эвтаназии и отношению к ней, вошли 16 психиатров и 19 терапевтов (которые работали в связке с психиатрами). Желание умереть, в представлении большинства из них, может относиться к одному из трех типов: импульсивная суицидальность (вызываемая текущими обстоятельствами), хроническая суицидальность (периодически возвращающаяся) и осознанное, непреходящее желание умереть, при этом первые два являются не более чем психопатологическими симптомами. Один из информантовпсихиатров, однако, сомневался, что такое явление, как «рациональное желание умереть», вообще существует - с его точки зрения, это лишь боль, гнев и отчаяние. Для других были важны факторы постоянства (пациент долго и неотступно поднимает вопрос о смерти) и отсутствия острой депрессии (хотя пациент не расстроен, он все же выказывает желание умереть); тем не менее не все информанты были уверены, что на эти факторы можно всецело полагаться. Весомой причиной отказа в эвтаназии для всех информантов являлся риск совершения пациентом самоубийства или непосредственная угроза с его стороны покончить с собой, если ему откажут в эвтаназии, поскольку, по мнению врачей, это две разных ситуации, два разных желания и даже две разных группы пациентов: из стремящихся к эвтаназии меньшинство склонны к совершению самоубийства.

Таким образом, непосредственно принимая решение об эвтаназии, респонденты стремились руководствоваться тремя факторами: помимо неизлечимости болезни и тяжести страданий, особую роль играет осознанность просьбы об эвтаназии. Убедиться в последнем, по их мнению, должно помочь наблюдение за пациентом, а именно за следующими показателями: постоянна ли его просьба об эвтаназии; не возвращается ли к нему, пусть и редко, желание жить; взвешивает ли он все «за» и «против»; не пытается 


\section{Евсеева Я.В.}

ли манипулировать врачом; не начинает ли сомневаться, получив одобрение. При этом ряд участников исследования не скрывали, что считают эвтаназию «хорошей смертью» для тех пациентов, которые соответствуют критериям, так как, с их точки зрения, это достаточно спокойный и комфортный способ расстаться с жизнью, который позволяет подготовиться к уходу - и им самим, и их близким.

Данный обзор показал, что развитие практики эвтаназии отражает все большую автономию индивидов в современных западных обществах. Однако желание пациентов принимать независимые решения в отношении не только своей жизни, но и смерти может войти в противоречие как с профессиональными обязанностями врачей, так и с принципом оказания наилучшего лечения и ухода. Тем не менее в глобализованном мире западные общества испытывают влияние иных культур, в частности в западные страны, чье население в большинстве своем расположено к эвтаназии, прибывает все больше медицинских работников из стран, для которых характерно негативное отношение к этому явлению. Также практика эвтаназии может претерпеть изменения в новой постковидной реальности.

\section{Список литературы}

Attitudes toward euthanasia : a longitudinal analysis of the role of economic, cultural and health-related factors / Inglehart R.Ch., Nash R., Hassan Q.N., II, Schwartzbaum J. // J. of pain a. symptom management. - 2021. - Jan 22. - P. 1-11.

Biotti-Mache F. L'euthanasie : quelques mots de vocabulaire et d'histoire // Études sur la mort. - 2016. - N 2. - P. 17-33.

Developments in euthanasia practice in the Netherlands : balancing professional responsibility and the patient's autonomy / Kouwenhoven P.S.C., van Thiel G.J.M.W., van der Heide A., Rietjens J.A.C., van Delden J.J.M. // European j. of general practice. - 2019. - Vol. 25, N 1. - P. 44-48.

Inbadas H., Carrasco J.M., Clark D. Representations of palliative care, euthanasia and assisted dying within advocacy declarations // Mortality. - 2020. - Vol. 25, N 2. - P. 138-150.

Koksvik G.H. Medically timed death as an enactment of good death : an ethnographic study of three European intensive care units // OMEGA - j. of death a. dying. 2020. - Vol. 81, N 1. - P. 66-79.

Pronk R., Willems D.L., van de Vathorst S. Do doctors differentiate between suicide and physician-assisted death? A qualitative study into the views of psychiatrists 
and general practitioners // Culture, medicine a. psychiatry. - 2021. - Vol. 45, N 2. P. 268-281.

Van der Geest S., Satalkar P. Autonomy and dying : notes about decisionmaking and «completed life» euthanasia in the Netherlands // Death studies. - 2019. Oct 10. - P. 1-10. 